\title{
Dilemma of Interpretation of High Sensitivity Troponin in Non-ST Elevated Myocardial Infarction
}

Omar Yousef Al-assaf ( $\nabla$ alassaf_94@hotmail.com )

Dubai Health Authority https://orcid.org/0000-0002-3609-4622

Anas A. Abbas

Dubai Health Authority

Azan Salem BinBrek

Dubai Health Authority

Hind H. Alkazim

Dubai Health Authority

Sam Codampallil Benny

Dubai Health Authority

\section{Research article}

Keywords: Non-obstructive myocardial infarction, Cardiac biomarkers, Coronary Angiography, Non-ST elevated myocardial infarction

Posted Date: July 15th, 2020

DOI: https://doi.org/10.21203/rs.3.rs-42900/v1

License: (c) (i) This work is licensed under a Creative Commons Attribution 4.0 International License.

Read Full License 


\section{Abstract}

Background: Non-ST Elevated Myocardial Infarction (NSTEMI) diagnosis is dependent on elevation of high sensitivity troponin (hs-troponin). The current cutoff point for hs-troponin is highly sensitive but not specific for detecting obstructive myocardial infarction. Our aim is to better risk stratify patients by determining the significance of the current cut off point hs-troponin in determining obstructive myocardial infarction.

Methods: We studied 202 patients. All patients were assessed for their demographics, clinical history, laboratory and imaging results. Using SPSS version 22, the pooled cohort of patients were analyzed at significant level $<0.05$ and the data were test for significant correlations between two predetermined groups; A and B. Group A included patients with positive coronary angiography (CAG) results who had obstructive coronary artery disease and required intervention, and group $B$ included patients with negative CAG results who had normal or near normal coronary arteries that required no intervention.

Results: Group A comprised $87.6 \%$ of the patients. Both groups had a median age of 53 years. In Group A, $91 \%$ were males, $54 \%$ were diabetics, $54 \%$ hypertensives and median hs-troponin was $145 \mathrm{ng} / \mathrm{L}$. While in group B, $88 \%$ were males, $39 \%$ were diabetics, $60 \%$ hypertensives, and median hs-troponin was $54 \mathrm{ng} / \mathrm{L}$. There is significant correlation between the two groups in the percentage of diabetes and median troponin level $(p<0.05)$.

Conclusions: A ROC curve was generated and identified a level of $127 \mathrm{ng} / \mathrm{dL}$ as the best cutoff of hstroponin in detecting obstructive myocardial infarction ( $p=0.03)$. Interestingly, $60 \%$ of patients in group $B$ had alternative diagnosis.

\section{Background}

Acute coronary syndrome with normal or near normal coronary arteries (ACSNNOCA) commonly known as Myocardial Infarction/Injury with Non-obstructive Coronary Arteries (MINOCA) also known as Troponin positive non obstructive coronary artery (TP-NOCA), can be caused by etiologies of coronary disorders, myocardial disorders or non-cardiac disorders.[1-3] These etiologies include coronary spasm, microvascular dysfunction, myocarditis, hypertensive heart disease, stroke, sepsis, pulmonary embolism in addition to others. Moreover, these diseases overlap with type 2 myocardial infarction. $[1,4]$ Therefore, the challenge arises in making a decision whether the patient is suffering a myocardial injury, ischemia or infarction requiring intervention. [1]

These challenging situations have increased currently with the introduction of high sensitivity cardiac troponin assay in view of its low specificity. [1] In a review article by Pasupathy et al. the prevalence of MINOCA was reported as $6 \%$, ranging from $1-15 \%$. Moreover, $14 \%$ of patients with acute myocardial infarction have been found to have non-obstructive coronary artery disease defined as coronary stenosis of less than $50 \%$. Research has shown that two third of patient with MOINCA present and are admitted as Non-ST Elevation Myocardial Infarction (NSTEMI). [1, 3] 
Risk stratification in patients with NSTEMI is of extreme importance especially since multiple scores have been developed; Thrombolysis in Myocardial Infarction score (TIMI), HEART score and Global Registry of Acute Coronary Events (GRACE). [4] Moreover, risk stratification is emphasized as VIRGO study found the prevalence of MINOCA to be five times more in women than men and in patients with lower traditional cardiac risk factors and by another study which found MINOCA to be higher in younger patients. [5-8]

Our research aims to better risk stratify patients by determining statically if the current cutoff value of high sensitivity troponin (hs-troponin) is significant to indicate obstructive coronary artery myocardial infarction in NSTEMI.

\section{Methods}

\section{Study design:}

A one-year retrospective cohort study including patient's fulfilling the following inclusion criteria:

- Patients admitted between 1st of April 2018 through 31st of March 2019 in Rashid hospital as NSTEMI.

- Age $>18$ years old.

- Patients that have underwent Coronary angiography in the same index admission.

\section{Data Collection:}

The data was answered in a structured questionnaire and present in an excel spreadsheet including the following variables:

- Demographics (age, gender and ethnicity)

- Previous risk factors for cardiac disease (smoking, previous myocardial infarction, hypertension or diabetes)

- Laboratory findings (Low Density Lipoprotein value, Hemoglobin-A1C, and Highest hs-troponin value).

- Previous medication use (aspirin, statin or angiotensin - converting- enzyme inhibitors or angiotensin ii receptor blockers)

- Coronary Angiography (CAG) finding:

- Positive CAG: if patient had obstructive coronary artery disease or underwent a coronary intervention in the index admission.

- Negative CAG: if patient had normal or non-obstructive coronary artery disease.

\section{Data Analysis:}

SPSS software version 22 was used for statically analysis with confidence interval of $95 \%$ ( $p$-value equal to or less than 0.05 considered significant). 
For variables were their numerical data is non-skewed the Mean is reported (Hemoglobin and LDL) while for variables with skewed data the Median is reported (all other variables with numerical data). On the other hand, for the categorical variables the percentage within the CAG finding is reported. Correlation was investigated using T-test for non-skewed numerical data, Mann-Whitney test for skewed numerical data and chi-square test for categorical data.

\section{Ethical Approval:}

An ethics approval was obtained from Dubai Scientific Research Ethics Committee, DHA holding the reference number of DSREC/RRP/2019/13.

\section{Results}

\section{Descriptive Analysis}

202 patients fulfilled the inclusion criteria from the retrieved files. After which we grouped them into two groups. Group A (Positive CAG) included 177 patients (87.6\%) of which 91\% were males, meanwhile Group B (Negative CAG): 25 patients (12.4\%) of which $88 \%$ were males. The median age in both groups was 53 years old and Table. 1 illustrated different variables between the two groups.

Table.1 Comparison of different variables between CAG groups

\begin{tabular}{|llll|}
\hline Variables & Group & \multicolumn{2}{c|}{ P-Value } \\
\cline { 2 - 3 } & CAG Positive & CAG Negative & \\
\hline Smoker (\%) & 37 & 40 & 0.799 \\
\hline Diabetic (\%) & 54 & 39 & 0.014 \\
\hline Hypertensive (\%) & 54 & 60 & 0.588 \\
\hline Median hs-Troponin (ng/L) & 145 & 54 & 0.030 \\
\hline Median HBA1C (\%) & 6.100 & 5.750 & 0.135 \\
\hline Mean LDL (mg/dL) & 126.48 & 121.22 & 0.567 \\
\hline
\end{tabular}

On further Analysis of Cofounding variables are shown in Table.2, in which all variables had a $p$ value of $>0.05$. 
Table.2 Comparing cofounding variables between patients with positive coronary angiography finding to patients with a negative coronary angiography finding.

\begin{tabular}{|lll|}
\hline Variable & Group A (Positive CAG) & Group B (Negative CAG) \\
\hline Median Creatinine $(\mathrm{mg} / \mathrm{dL})$ & 0.9 & 0.8 \\
\hline Mean Hemoglobin $(\mathrm{g} / \mathrm{dL})$ & 14.25 & 14.21 \\
\hline Median CPK (mg/L) & 216 & 191 \\
\hline
\end{tabular}

\section{Troponin as a diagnostic biomarker for myocardial infarction}

To statistically measure the diagnostic cutoff value of troponin as a biomarker for NSTEMI a receiver operating characteristic curve (ROC) was obtained (Figure.1). CAG was considered as the gold standard test. The ROC analysis showed an Area Under the Curve (AUC) of 0.634 (0.51-0.751) with a p value of 0.03 and confidence interval of $95 \%$. Studying the sensitivities and specificities of the ROC curve; it was deduced that the best cutoff value for troponin is 127 .

\section{Discussion}

Troponin has been acknowledged as a biomarker for diagnosing and management for myocardial infarction in NSTEMI by the American Heart Association (AHA), American College of Cardiology (ACC) and the European Society of Cardiology $[9,10]$. However, the ACC and AHA emphasize that elevation of troponin is not always due to atherosclerotic coronary artery disease but might be only myocardial injury [9].

Currently, $14 \mathrm{ng} / \mathrm{L}$ is considered as the cutoff value for a positive troponin result. In studying our ROC curve at value 14 the sensitivity for a positive CAG for myocardial infarction is $99.9 \%$ however a specificity of only $4 \%$. Moreover, The AUC of the ROC curve was found to 0.634 indicating a low diagnostic accuracy $(<0.7)$, although statistically positive $(p<0.05)$ [11]. This directs that troponin is statistically significant as biomarker for myocardial infarction but clinically insignificant.

An alternative diagnosis was looked for in those that had a negative CAG for a myocardial infarction. Cardiac diagnosis was found in $32 \%$ of the negative CAG; included valvular diseases, arrhythmogenic cardiomyopathy, myopericarditis, myocarditis, chest trauma and arrythmias; bigeminy, ventricle tachycardia and supraventricular tachycardia. This indicates that the elevated troponin in these patients was due to a myocardial injury rather than a myocardial infarction. Furthermore, $20 \%$ of the negative CAG group had other non-cardiac alternative diagnosis found were bladder cancer, sarcoidosis, H.Pylori infection, gastric ulcer and anemia. In these patients with non-cardiac alternative diagnoses their troponin results ranged from $26-126 \mathrm{ng} / \mathrm{L}$ supporting our ROC curve troponin cutoff point of 127 . In addition, 
several published articles support that the prior found alternative cardiac and non-cardiac diagnoses elevated troponin but have no significant cardiac coronary infarction [12-16].

\section{Conclusion}

Our research concludes several points. Firstly, in patients with low risk of myocardial infarction presenting as NSTEMI an alternative diagnosis should be looked for when hs-troponin level is lower than $127 \mathrm{ng} / \mathrm{L}$. Moreover, although hs-troponin is a good biomarker in determining myocardial infarction in NSTEMI, it holds a low specificity at the current cutoff point of $14 \mathrm{ng} / \mathrm{L}$. Therefore, Hs-troponin cannot be used alone as an indicator of myocardial infarction without other clinical evidences. Lastly, since more than $50 \%$ of our patients in the negative CAG group had alternative diagnosis; through history, physical examination, laboratory testing, radiological imaging and non-invasive measures are recommended for patients with hs-troponin levels below the purposed new level.

\section{Abbreviations}

NSTEMI: Non-ST Elevation Myocardial Infarction

ACS: Acute Coronary Syndrome

Hs-troponin: High sensitivity troponin

CAG: Coronary angiography

AUC: Area Under the Curve

ROC: receiver operating characteristic curve

AHA: American Heart Association (AHA),

ACC: American College of Cardiology (ACC)

ACSNNOCA: Acute coronary syndrome with normal or near normal coronary arteries

MINOCA: Myocardial Infarction/Injury with Non-obstructive Coronary Arteries

TP-NOCA: Troponin positive non obstructive coronary artery

\section{Declarations}

\section{Ethical Approval and consent to participate:}

An ethics approval was obtained from Dubai Scientific Research Ethics Committee, DHA holding the reference number of DSREC/RRP/2019/13. 


\section{Availability of Data and material}

Data is available with the authors in an excel sheet.

\section{Competing interests}

Authors have no relationships relevant to the contents of this paper to disclose.

\section{Funding}

No funding source was for this manuscript.

\section{Authors' Contributions}

All Authors have read and approved the manuscript

OA: Has did the data collection and statistic analysis.

AA Has formulated the methodology, did the data base of variable collection and written a part of the discussion.

$A B$ : Formulated the aim of the research and assured integrate of the scientific content. In addition, edited the final manuscript.

HA: Has help in the data collection and written a part of the discussion.

SB: Has provided the patients files that fulfil the inclusion criteria and edited the final manuscript.

\section{Acknowledgments:}

The authors would like to thank Dr. Marwan Zidan for statistic studies and the Cardiology Department of Rashid Hospital for their support.

\section{References}

1. Pustjens, T.F.S., Appelman, Y., Damman, P. et al. Guidelines for the management of myocardial infarction/injury with non-obstructive coronary arteries (MINOCA): a position paper from the Dutch ACS working group. Neth Heart J (2019). https://doi.org/10.1007/s12471-019-01344-6

2. Collste $\mathrm{O}$, Sorensson P, Frick $\mathrm{M}$, et al. Myocardial infarction with normal coronary arteries is common and associated with normal findings on cardiovascular magnetic resonance imaging: results from 
the Stockholm Myocardial Infarction with Normal Coronaries study. J Intern Med.2013;273(2):18996.

3. Pasupathy S, Tavella R, Beltrame JF. Myocardial infarction with Nonobstructive coronary arteries (MINOCA):the past, present , and future management. Circulation. 2017;135(16):1490-3

4. Ezra A. Amsterdam, Nanette K. Wenger, Ralph G. Brindis, Donald E. Casey, Theodore G. Ganiats, David R. Holmes, Allan S. Jaffe, Hani Jneid, Rosemary F. Kelly, Michael C. Kontos, Glenn N. Levine, Philip R. Liebson, Debabrata Mukherjee, Eric D. Peterson, Marc S. Sabatine, Richard W. Smalling, Susan J. Zieman. J Am Coll Cardiol. 2014 Dec, 64 (24) e139-e228.

5. Roe M T, Harrington R A, Prosper D M, etal. Clinical and therapeutic profile of patients presenting with acute coronary Syndromes who do not have significant coronary artery disease. The Platelet Glycoprotein Ilb/Illa in Unstable Angina: Receptor Suppression Using Integril in Therapy (PURSUIT) trial investigators. Circulation. 2000;102(10):1101-6

6. Safdar B, Spatz ES, Dreyer RP, et al. Presentation, clinical profile, and prognosis of young patients with myocardial infarction with nonobstructive coronary arteries (MINOCA): results from the VIRGO study. J Am Heart Assoc. 2018; https://doi.org/10.1161/JAHA.118.009174.

7. Larsen Al, Nilsen DW, Yu J, et al. Long-term prognosis of patients presenting with ST-segment elevation myocardial infarction with no significant coronary artery disease (from the HORIZONS-AMI trial). Am J Cardiol. 2013;111(5):643-8

8. Patel MR, Chen AY, Peterson ED, et al. Prevalence, predictors, and outcomes of patients with non-STsegment elevation myocardial infarction and insignificant coronary artery disease: results from the Can Rapid risk stratification of Unstable angina patients Suppress Aderse outcomes with Early implementation of the ACC/AHA Guidelines (CRUSADE)initiative. AmHeartJ.2006;152(4):641-7

9. Braunwald E, Antman EM, Beasley JW, et al. ACC/AHA 2002 guideline update for the management of patients with unstable angina and non-ST-segment elevation myocardial infarction - summary article: a report of the American College of Cardiology/American Heart Association task force on practice guidelines (Committee on the Management of Patients With Unstable Angina) J Am Coll Cardiol. 2002;40:1366-1374.

10. Alpert JS, Thygesen K, Antman E, et al. Myocardial infarction redefined - a consensus document of The Joint European Society of Cardiology/American College of Cardiology Committee for the redefinition of myocardial infarction. J Am Coll Cardiol. 2000;36:959-969.

11. Mandrekar J. Receiver operating characteristic curve in diagnostic test assessment. J Thorac Oncol. 2010; 5(9):1315-1316. doi: 10.1097/JT0.0b013e3181ec173d.

12. Korff S., Katus H., Giannitsis E. Differential diagnosis of elevated troponins. Heart 2006; 92:987-993. doi: 10.1136/hrt.2005.071282

13. Kanjwal, K., Imran, N., Grubb, B., \& Kanjwal, Y. (2008). Troponin elevation in patients with various tachycardias and normal epicardial coronaries. Indian pacing and electrophysiology journal, 8(3), 172-174. 
14. Kelley W, Januzzi J, Christenson R. Increases of Cardiac Troponin in Conditions other than Acute Coronary Syndrome and Heart Failure. Clinical Chemistry. 2009; 55(12): 2098-2112.

15. Ralli S, Horwich TB, Fonarow GC. Relationship between anemia, cardiac troponin I, and B-type natriuretic peptide levels and mortality in patients with advanced heart failure. Am Heart $\mathrm{J}$. 2005;150(6):1220-1227.

16. Kandolin R, Lehtonen J, Airaksinen J, Vihinen T, Miettinen H, Kaikkonen K, Haataja P, Kerola T, Kupari M. Usefulness of cardiac troponins as markers of early treatment response in cardiac sarcoidosis. Am J Cardiol 2015;116:960-964.

\section{Figures}




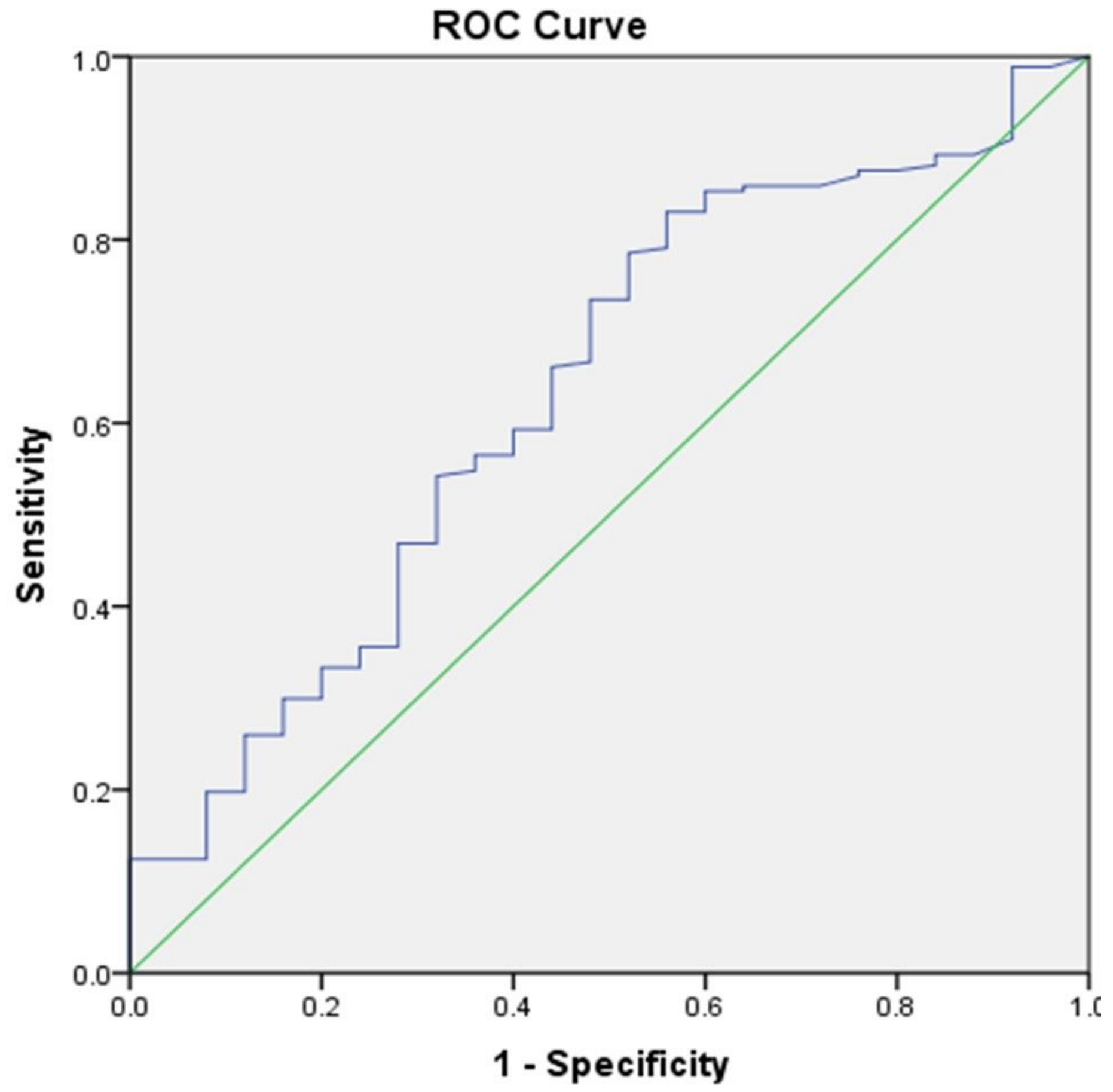

Diagonal segments are produced by ties.

Figure 1

ROC Curve of our data

\section{Supplementary Files}

This is a list of supplementary files associated with this preprint. Click to download. 
- Questionnaire.xIsx

Page $11 / 11$ 